\title{
The use of High Resolution CT (HRCT) for the Evaluation of Lung Parenchyma in patient with Arthritis
}

\author{
Hussnain Rashid Butt ${ }^{*}$, Muhammad Ahmad Naeem ${ }^{2}$, Akash John $^{3}$, Nosheen Arshad ${ }^{4}$, SadiaAzam $^{5}$, Abid Ali $^{6}$ \\ ${ }^{1}$ Medical Imaging Doctor, Department of Radiology Sciences and Medical Imaging, the University of Lahore, Gujrat, Pakistan \\ ${ }^{2-5}$ Lecturer, Department of Radiology Sciences and Medical Imaging, the University of Lahore, Gujrat Pakistan \\ ${ }^{6}$ Associate Professor, Department of Allied Health Sciences, the University of Lahore, Gujrat, Pakistan
}

$\begin{array}{cl}\text { Article History } & \begin{array}{l}\text { Abstract: Background: Interstitial lung disease is an umbrella term used for a group of } \\ \text { diseases that causes scaring, swelling, infection, Inflammation, Fibrosis and difficulty in } \\ \text { Received: } 27.01 .2021\end{array} \\ \text { breathing. HRCT is Gold standard modality to evaluate ILDS in RA patients because there } \\ \text { are different appearances shows on CT in lungs that are used to evaluate the severity and } \\ \text { Published: } 26.03 .2021 \\ \text { extend of disease in lungs. Objective: To emphasize the use of High Resolution Computed } \\ \text { Tomography in patients of arthritis having Lung parenchymal diseases. Methodology: An } \\ \text { observation study of RA-ILD patients surveyed from May to November 2020.The } 60 \\ \text { patients where ruled out with Arthritis in our Clinical Centre out of which } 22 \text { patients were } \\ \text { taken to investigate that appearances like Ground glass, Honey comb, Enlarged lymph } \\ \text { nodes, Bronchiectasis, Pleural effusion in the patients of Rheumatoid Arthritis. Result: In } \\ \text { this study 22 patients were taken out of which Arthritis was present in 18 Patient and we } \\ \text { evaluated the HRCT findings like Ground glass opacities, Honey comb appearance, lymph } \\ \text { nodes, Bronchiectasis, Pleural effusion. Frequencies of different (ILDs) HRCT appearances } \\ \text { were obtained. These outcomes recommend a positive relationship between the RA infection } \\ \text { action and Lung aggravation in RA-ILD. Conclusion: In conclusion lung parenchymal } \\ \text { changes due to Rheumatoid arthritis are more common in male than female. HRCT } \\ \text { demonstrated sensitivity in the detection of anomalies, but clinically silent as well as not } \\ \text { being diagnosed in simple radiography. It concludes that HRCT images are beneficial in } \\ \text { diagnosing interstitial lung disease for rheumatoid arthritis patients. } \\ \text { Keywords: High Resolution Computed Tomography Rheumatoid Arthritis, Interstitial Lung } \\ \text { Diseases, Ground Glass Appearance, Honey Comb Appearance, enlarged Lymph Node, } \\ \text { Bronchiectasis. }\end{array}$

Copyright ( 92021 The Author(s): This is an open-access article distributed under the terms of the Creative Commons Attribution 4.0 International License (CC BY-NC 4.0) which permits unrestricted use, distribution, and reproduction in any medium for non-commercial use provided the original author and source are credited.

\section{INTRODUCTION}

Rheumatoid Joint pain is a persistent inflammatory illness and it impacts about the majority of individuals now a days and it likewise influence about $1 \%$ of white populace around the world. Rheumatoid joint inflammation (RA) is the most generally experienced connective tissue sickness. RA can affect pleura, airways, and the lung Parenchyma [1]. Rheumatoid joint pain (RA) is a foundational immune system sickness described by symmetric polyarthritis that prompts reformist bone decimation and possible joint deformation whenever left untreated [2]. Early assessment of ILD is significant for the management of RA patients. Pulmonary manifestations can affects all the components of lungs with differing types of irritation and fibrosis [3].

Lung disease is also associated with Arthritis and is very common [4]. Lung sickness is second most basic reason of death (with $18 \%$ of patients with RA), after contamination [5] Respiratory disease more commonly develops in men. RA related lung sickness incorporates: interstitial lung infections (ILD) or common interstitial pneumonia (UIP), arranging pneumonia (OP), vague interstitial pneumonia (NSIP), and diffuse alveolar harm (DAD); aviation route illnesses like bronchitis aspiratory vascular infection, and rheumatoid knobs [5]. Also pneumonic contamination and medication poisonous are intermittent confusions of RA lung sickness directly connected with the fundamental RA is more normal [4]. It shows the same number of various subtypes, and regular interstitial pneumonia (UIP) is one of the most well-known sorts while it is suggested in nonunequivocal UIP cases, the vast majority of the patients don't go through careful lung biopsy due to the high dangers related with it $[3,6]$. So for the conclusion of RA-ILD is these days essentially dependent on highresolution computed tomography, (HRCT) [6]. 
The First Report about Lung disease, related to RAE llman and Ball in 1948 [7], when the systemic nature of 'rheumatoid disease' was just becoming appreciated HRCT is a technique introduced in mid1980 s result of significant improvement in the CT process and in computers [8,9]. On the other hand HRCT is an ideal and Noninvasive method of imaging when ILD is suspected [10]. Subsequently, clear techniques for giving aftereffects of infection degree are as yet required, so the reports of the endurance relationship of perceptions made with HRCT have basically centered in a wide range of illnesses that are related with ILD [11].

The histo pathological examination has a decent relationship with Honey Combing and Reticulation when it is seen on HRCT [12]. High resolution Computed Tomography can likewise show pictures (Ground-glass mistiness) and it associate incendiary harm in pathological investigation of lung tissues [10]. These sorts of pictures are estimated with records which are introduced by the Kazerooni et al.[10].

The amount of slice thickness moved with slice thickness and the degree of lungs in different patients [13]. while on the other hand High resolution computed Tomography has become a cutting edge test for the detection of patients with various basic clinical complaints, incorporating patients with dyspnea and constant hack. HRCT allows to separate regions of possibly reversible infection from irreversible fibrosis and furthermore valuable in showing the best example and site of lung biopsy [14]. Structural alterations in the lungs can be perfectly visualized in patients with normal findings on the chest radiographs [15].

Furthermore, HRCT-derived scores for to correlate them with degree of physiological deficiency and fibrosis extent [4] while the fundamental part of HRCT is arranging and checking IPF or ILD after some time and the large test for radiologists is the likelihood to conjecture the sickness course (slow or quick) at the hour of conclusion $[4,16]$. However, prone position is useful in assessing the interstitial lung disease involving dependent portions of the lung [15].

Thin Section chest CT is an exact and delicate method for the assessment of ILD. In examination with normal CT, HRCT have the capacity to identify little structures, including interlobular septa, development dividers, interstitial septa, and bronchial dividers, by using High Spatial Frequency remaking Algorithms, extending spatial objective and reducing picture smoothing [17]. Normal chest radiographs are not delicate while the reported rate of ILD dependent on chest $\mathrm{x}$-beams is $1-5 \%$. The assessed prevalence of RAILD utilizing HRCT is $20-44 \%$.
The study was to assess the Lung parenchyma by using HRCT in the Patients with RA and the use of HRCT for treating and diagnosing ILD because HRCT is Gold stander for the evaluation of ILD as compare it with normal $\mathrm{Ct}$ scan it is not as much useful for diagnosis and treatment while this study will also help to understand the modification in CT scans and there use in Lung diseases[18].

\section{Patients and Methods}

A study that included patients from an accomplice of RA-ILD patients surveyed from May to November 2020.The 60 patients where ruled out with Arthritis in our Clinical Centre out of which 22 patients were taken to investigate that which appearance is more common in patients ARA rules for rheumatoid joint irritation [19]. All the patients referred to our foundation, it's a public clinical reference place for respiratory sicknesses, to assess their pneumonic side effects and I was doing rotation there. All patients are assessed by the experienced pulmonologist who have good experience in Interstitial lung disease radiologist and also with a rheumatologist whose experience is good in ILD-R]20].When Rheumatoid Arthritis with ILD was characterized as the reason for aspiratory indications and different reasons for pneumonic irregularities were avoided, the treatment chosen in agreement of the going to pulmonologist and then to rheumatologist After the total assessment of the patients in the ILD Department, patients were treated with DMARDs in immunotherapy or blend (Methotrexate, Leflunomide, Sulphasalazine or Azathioprine) notwithstanding Corticosteroids'. All these things are done by the consent of the patient because it is very important to tell about everything that is happening to the patient.

\section{High resolution computed tomography scan}

HRCT was performs with 1.0 or $2.0 \mathrm{~mm}$ thick pivotal segment taken at $2 \mathrm{~cm}$ spans all through entire chest, they were remade utilizing a High-spatial recurrence calculation. Somewhere in the range of 20 to $30 \mathrm{CT}$ filter pictures were obtained in every patients scan. High resolution Computed Tomography was assessed by radiologist that is present in Clinical centre. In brief, peruser notices 3 pictures that are taken at Aortic Curve Level, the carina, $1 \mathrm{~cm}$ over stomach the afterward, givesa score on a size for both alveolar and ILD abnormality from 0 to 5 as indicated by plan introduced by Kazerooni et al.4 Then from the obtained images a normal picture is determined. In most of the patients we found arthritis and the patients with Ground glass appearance are more common as compare to other appearances. The contrast study is beneficial in this case because its gives us detail image in HRCT as compare to Normal image. The patients with serious condition are on follow up and the medications that are given to them are DMARDs and Antibiotics that helps to fight against disease. 
Hussnain Rashid Butt et al; EAS J Radiol Imaging Technol; Vol-3, Iss-2 (Mar-Apr, 2021): 49-56

\begin{tabular}{|c|l|r|r|r|r|r|}
\hline \multirow{2}{*}{$\mathrm{N}$} & \multicolumn{1}{|c|}{$\begin{array}{l}\text { Is Ground glass } \\
\text { opacities present }\end{array}$} & $\begin{array}{c}\text { Is Honey Comb } \\
\text { appearance present }\end{array}$ & $\begin{array}{c}\text { Is Bronchietasis } \\
\text { present }\end{array}$ & $\begin{array}{c}\text { Is Pleuraleffusion } \\
\text { Present }\end{array}$ & $\begin{array}{c}\text { Is Enlarged lymph } \\
\text { nodes present }\end{array}$ \\
\cline { 2 - 8 } & Valid & 22 & 22 & 22 & 22 & 22 \\
\cline { 2 - 8 } & Missing & 0 & 0 & 0 & 0 & 0 \\
\hline
\end{tabular}

\section{Statistics}

\begin{tabular}{|c|c|c|c|c|c|c|c|}
\hline \multicolumn{8}{|c|}{ CORRELATIONS } \\
\hline & & & $\begin{array}{l}\text { Is Ground } \\
\text { glass } \\
\text { opacities } \\
\text { present }\end{array}$ & $\begin{array}{l}\text { Is } \\
\text { Bronchieta } \\
\text { sis present }\end{array}$ & $\begin{array}{l}\text { Is Honey } \\
\text { Comb } \\
\text { appearance } \\
\text { present }\end{array}$ & $\begin{array}{l}\text { Is } \\
\text { Pleuraleffu } \\
\text { sion } \\
\text { Present }\end{array}$ & $\begin{array}{l}\text { Is Enlarged } \\
\text { lymph nodes } \\
\text { present }\end{array}$ \\
\hline \multirow{15}{*}{$\begin{array}{l}\text { Spearman's } \\
\text { rho }\end{array}$} & \multirow{3}{*}{$\begin{array}{l}\text { Is Ground glass } \\
\text { opacities present }\end{array}$} & $\begin{array}{l}\text { Correlation } \\
\text { Coefficient }\end{array}$ & 1.000 & -.140 & $-.690^{* * *}$ & .121 & .332 \\
\hline & & Sig. (2-tailed) & . & .535 & .000 & .592 & .131 \\
\hline & & $\mathrm{N}$ & 22 & 22 & 22 & 22 & 22 \\
\hline & \multirow{3}{*}{$\begin{array}{l}\text { Is Bronchietasis } \\
\text { present }\end{array}$} & $\begin{array}{l}\text { Correlation } \\
\text { Coefficient }\end{array}$ & -.140 & 1.000 & .388 & -.388 & $-.624^{* * *}$ \\
\hline & & Sig. (2-tailed) & .535 & & .074 & .074 & .002 \\
\hline & & $\mathrm{N}$ & 22 & 22 & 22 & 22 & 22 \\
\hline & \multirow{3}{*}{$\begin{array}{l}\text { Is Honey Comb } \\
\text { appearance present }\end{array}$} & $\begin{array}{l}\text { Correlation } \\
\text { Coefficient }\end{array}$ & $-.690^{* * *}$ & .388 & 1.000 & -.083 & $-.574^{* *}$ \\
\hline & & Sig. (2-tailed) & .000 & .074 & & .712 & .005 \\
\hline & & $\mathrm{N}$ & 22 & 22 & 22 & 22 & 22 \\
\hline & \multirow{3}{*}{$\begin{array}{l}\text { Is Pleural effusion } \\
\text { Present }\end{array}$} & $\begin{array}{l}\text { Correlation } \\
\text { Coefficient }\end{array}$ & .121 & -.388 & -.083 & 1.000 & .203 \\
\hline & & Sig. (2-tailed) & .592 & .074 & .712 & . & .366 \\
\hline & & $\mathrm{N}$ & 22 & 22 & 22 & 22 & 22 \\
\hline & \multirow{3}{*}{$\begin{array}{l}\text { Is Enlarged lymph } \\
\text { nodes present }\end{array}$} & $\begin{array}{l}\text { Correlation } \\
\text { Coefficient }\end{array}$ & .332 & $-.624^{* *}$ & $-.574^{* * *}$ & .203 & 1.000 \\
\hline & & Sig. (2-tailed) & .131 & .002 & .005 & .366 & \\
\hline & & $\mathrm{N}$ & 22 & 22 & 22 & 22 & 22 \\
\hline & & & Statistics & & & & \\
\hline
\end{tabular}

\section{HISTOGRAM}

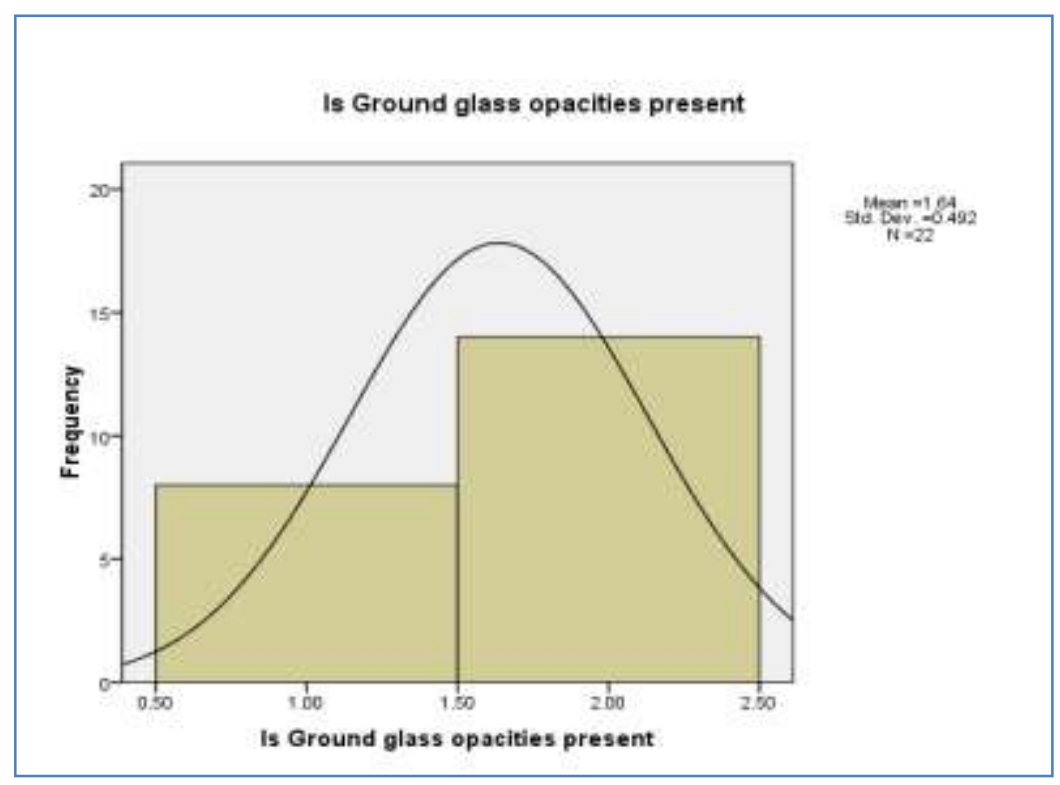

Is Ground glass opacities present

\begin{tabular}{|l|l|r|r|r|r|}
\hline \multicolumn{7}{|c|}{ Is Ground glass opacities present } \\
\hline \multirow{3}{*}{ Valid } & & Frequency & Percent & Valid Percent & Cumulative Percent \\
\cline { 2 - 6 } & yo & 8 & 36.4 & 36.4 & 36.4 \\
\cline { 2 - 6 } & Total & 14 & 63.6 & 63.6 & 100.0 \\
\hline
\end{tabular}




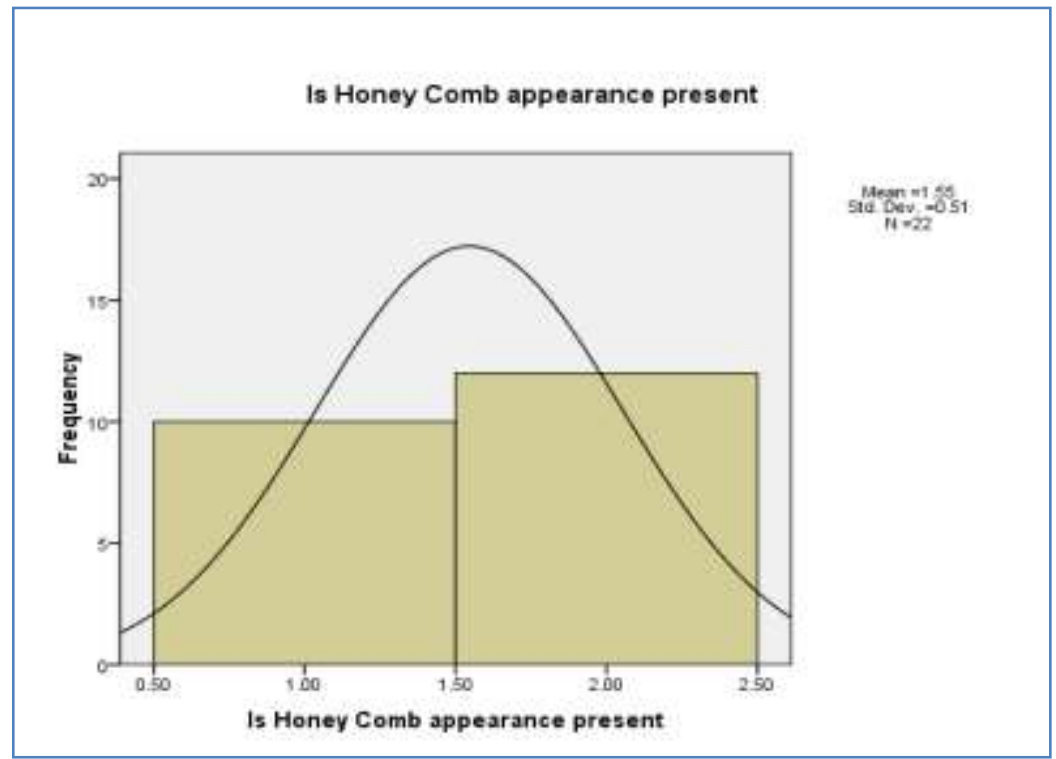

\begin{tabular}{|l|l|r|r|r|r|}
\hline \multicolumn{7}{|c|}{ Is Honey Comb appearance present } \\
\hline \multirow{3}{*}{ Valid } & & Frequency & Percent & Valid Percent & \multicolumn{1}{c|}{ Cumulative Percent } \\
\cline { 2 - 6 } & Yes & 10 & 45.5 & 45.5 & 45.5 \\
\cline { 2 - 6 } & No & 12 & 54.5 & 54.5 & 100.0 \\
\cline { 2 - 6 } & Total & 22 & 100.0 & 100.0 & \\
\hline
\end{tabular}

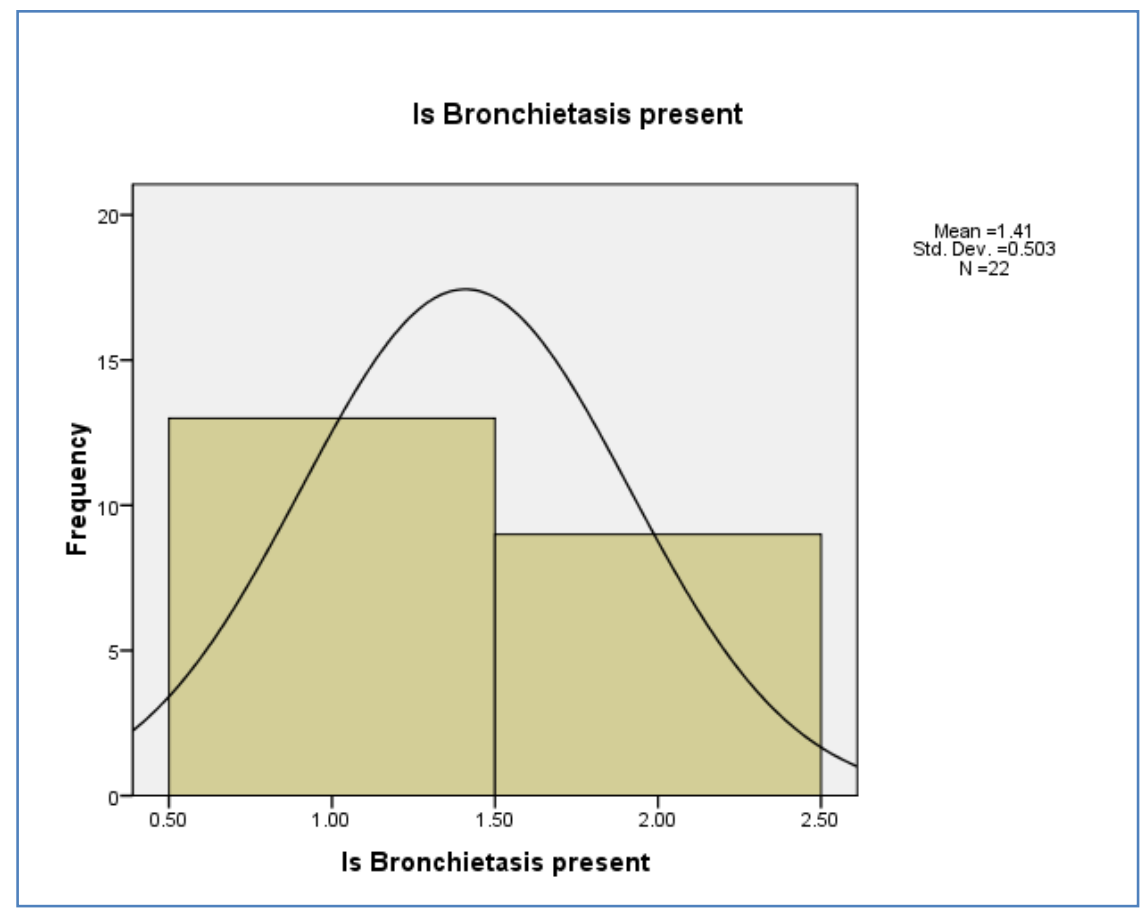

\begin{tabular}{|l|l|r|r|r|r|}
\hline \multicolumn{7}{|c|}{ Is Bronchietasis present } \\
\hline & & Frequency & Percent & Valid Percent & \multicolumn{1}{c|}{ Cumulative Percent } \\
\hline \multirow{3}{*}{ Valid } & yes & 13 & 59.1 & 59.1 & 59.1 \\
\cline { 2 - 6 } & No & 9 & 40.9 & 40.9 & 100.0 \\
\cline { 2 - 6 } & Total & 22 & 100.0 & 100.0 & \\
\hline
\end{tabular}




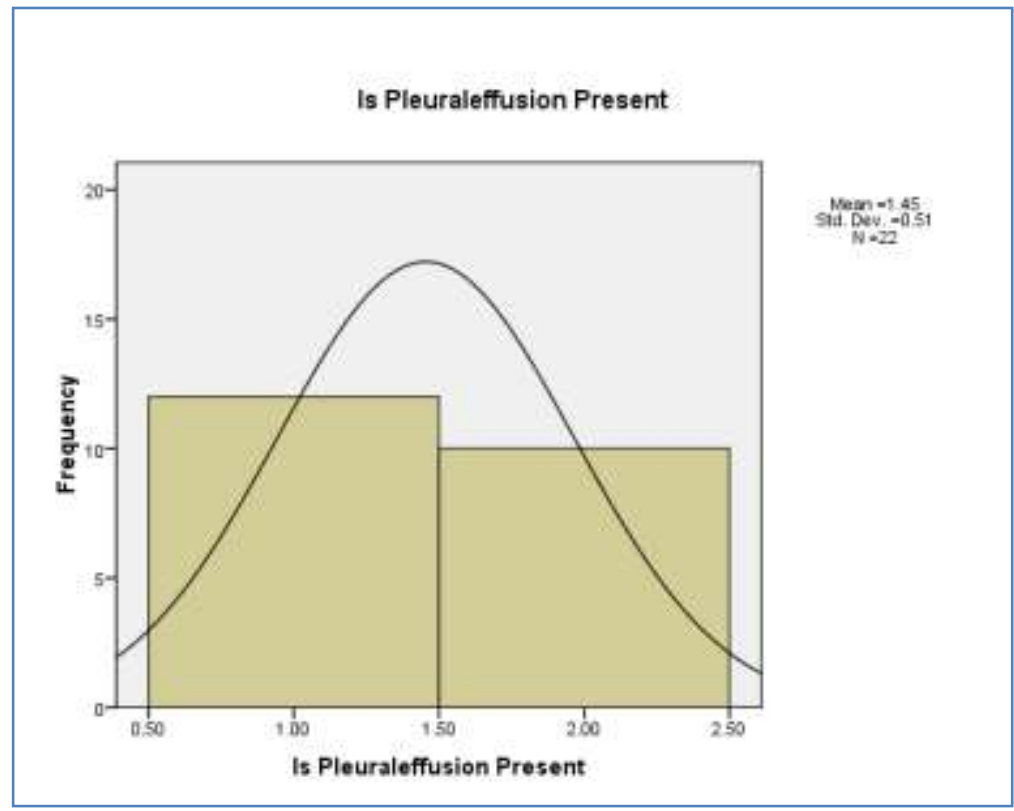

\begin{tabular}{|l|l|r|r|r|r|}
\hline \multicolumn{7}{|c|}{ Is Pleural effusion Present } \\
\hline \multirow{3}{*}{ Valid } & Yes & Frequency & Percent & \multicolumn{1}{|c|}{ Valid Percent } & \multicolumn{2}{c|}{$\begin{array}{c}\text { Cumulative } \\
\text { Percent }\end{array}$} \\
\cline { 2 - 6 } & No & 12 & 54.5 & 54.5 & 54.5 \\
\cline { 2 - 6 } & Total & 10 & 45.5 & 45.5 & 100.0 \\
\hline
\end{tabular}

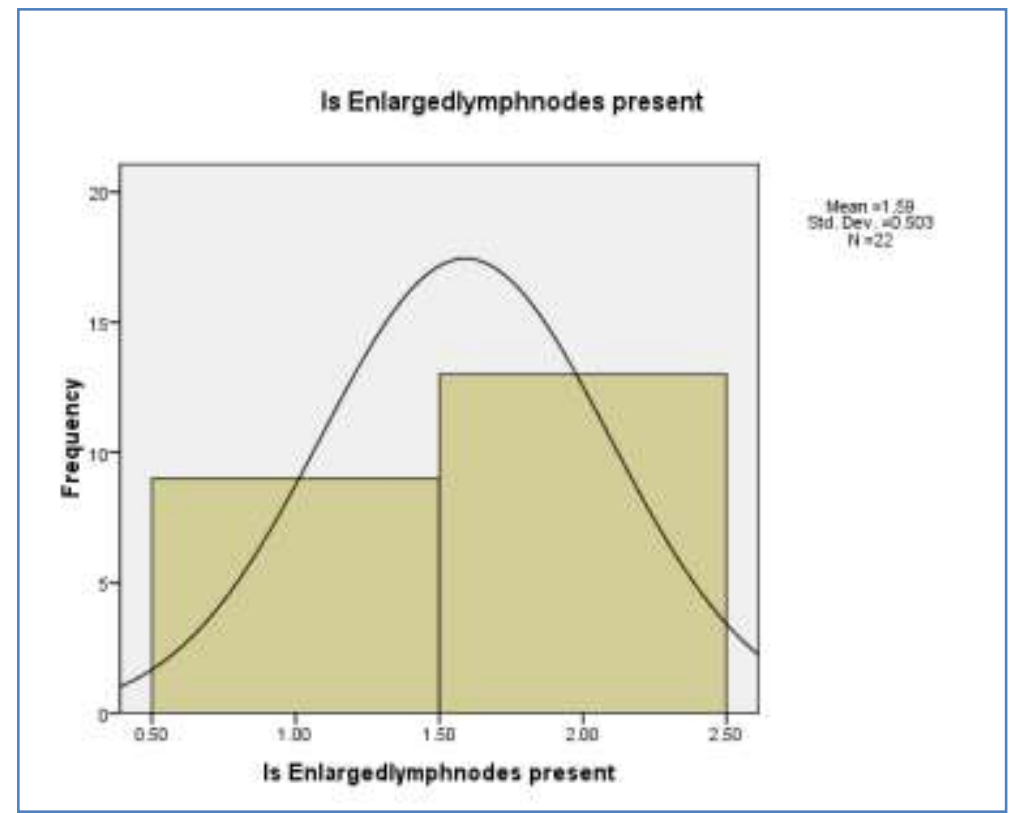

\begin{tabular}{|l|l|r|r|r|r|}
\hline \multicolumn{7}{|c|}{ Is Enlarged lymph nodes present } \\
\hline \multirow{3}{*}{ Valid } & & Frequency & Percent & Valid Percent & Cumulative Percent \\
\cline { 2 - 6 } & yo & 9 & 40.9 & 40.9 & 40.9 \\
\cline { 2 - 6 } & Total & 13 & 59.1 & 59.1 & 100.0 \\
\hline
\end{tabular}

\section{Statistical Analysis}

In this study we use statistical tool of Spearman's rank correlation coefficient by using SPSS.
It is used to evaluate the association between Ground glass opacities, Honey comb appearance, Enlarged lymph nodes, Bronchitis, Pleural effusion. First we put the data and set data labels and assign values and 
variables. Then we go into the analysis and after selecting the correlate option there is bivariate option through which we select the spearman's rank correlationthe alpha was set at, 2 followed. All examination finished with statistical bundle.

\section{RESULT}

In this study we have taken 22 patientsout of which Arthritis was present in 18 Patient whose percentage is $81.8 \%$ and then we evaluate the HRCT findings like Ground glass opacities, Honey comb appearance, Enlarged lymph nodes, Bronchiectasis, Pleural effusion. The ground glass opacities were present in 8 patients whose percentage was $36.4 \%$ and it was not present in 14 patients whose Percentage range was $63.6 \%$. After that we evaluate the honey Comb Appearance in RA patient and it was about present in 10 patients whose frequency was $45.5 \%$ and was not present in 12 patients whose frequency was $54.5 \%$. A part from this we also consider the presence of Bronchietasis in RA patient was about present in 13 patients out of 22 patients and its frequency was $59.1 \%$ and was not present in 9 patients and its percentage was about $40.9 \%$. While the Pleural effusion was present in 12 patients and its percentage was $54.5 \%$ and was not present in 10 patients and its percentage was $45.5 \%$ at the last we evaluate the Enlarged lymph node findings and it was present in 9 patients whose percentage was $40.9 \%$ and was not present in 13 patients whose percentage was $59.1 \%$. Significant aspects associated with HRCT anomalies were patients with age above 40 years, because in this study we take patient ranging from $30 \mathrm{yrs}$ to $70 \mathrm{yrsIgM}$ rheumatoid factor positive exams, rest hypoxia, and distal airway disorder LFT evidence. These outcomes recommend a positive relationship between the RA infection action and Lung aggravation in RA-ILD.

\section{Ground Glass Finging in HRCT}
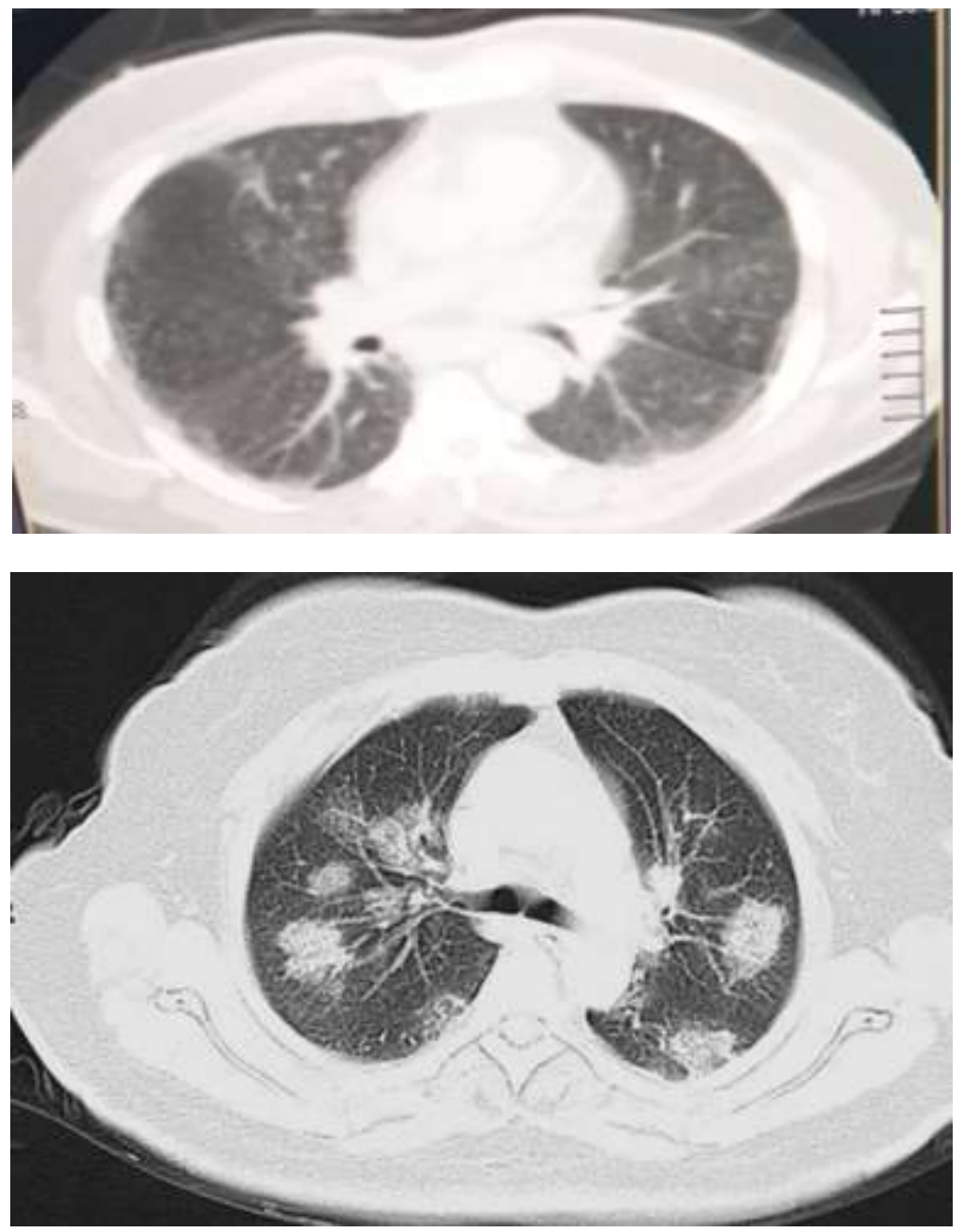

\section{DISCUSSION}

The consequence of examination shows a relationship between RA infection movement and lung aggravation assessed by High Resolution Computed Tomography in Rheumatoid Arthritis-Interstitial Lung Disease patients..Therefore theconsequences of the investigation are as per the theory that lung aggravation 
are seen in RAILD patients evaluated by HRCT is assistant to RA activity. The impression of this evaluation is that the Kazerooni ground-glass score and the CDAI score, yet not quantifiably huge, had lower scores after clinical treatment with DMARDs and prednisone.

In 2018 , Hanna M. Nurmi studied in Finland on about 60 Patients on different Interstitial disease and then compare the presence and Extent of disease by using a Scoring system then they collect the data from a hospital by using the variable like Age, Gender etc. and then correlate there positive and negative result for their scoring rate and reviled that Numerous radiological discoveries partner with the course of the sickness of RA-ILD and might be valuable when arranging the RA therapy or assessing the danger of death in these patients [6].

A section from this Luling Li in2019 surveys lung varieties from the HRCT and clarifies which oddity can anticipate the reformist fibrosis of rheumatoid joint irritation (RA) - related interstitial lung ailment (ILD). He studied on 1096 patient out of which 213 patient where diagnosed with RA-ILD by using HRCT they also take their clinical data and background history. The rate of ILD was increase in older age patients, the patient with smoking history, previous lung disease history etc. After that they take the percentages of the common disease and at the last they calculate the specificity and sensitivity ratio of most common two diseases that were diagnosed on $\mathrm{Ct}$. The amassed appraisal of these two CT inconsistencies has an achievable data [13].

\section{CONCLUSION}

This study concludes lung parenchymal changes due to Rheumatoid arthritis are more common in male than female. Joint stiffness, joint swelling, chest discomfort is also 22 patients were evaluated out of which RA was present in 18 patients. The ground glass opacities were present in 8 patients whose percentage was $36.4 \%$.Then we evaluate the honey Comb Appearance in RA patient and it was about present in 10 patients whose frequency was $45.5 \%$. Bronchietasis in RA patient was about present in 13 patients out of 22 patients and its frequency was $59.1 \%$. The Pleural effusion was present in 12 patients and its percentage was $54.5 \%$. Enlarged lymph node findings and it was present in 9 patients whose percentage was $40.9 \%$. The sample analyzed in patients with rheumatoid arthritis, HRCT demonstrated sensitivity in the detection of anomalies, but clinically silent as well as not being diagnosed in simple radiography. Correlations between HRCT anomalies were inconsistent, and investigation results varied. It is concluded that HRCT images are beneficial in diagnosing interstitial lung disease for rheumatoid arthritis patients. This modality may use for reticular abnormalities, with a predominance in the middle to upper lung fields in future research study.

\section{Ethical considerations}

The creator announce that the procedures followed were according to the rules of reliable Clinical Research Ethics Committee and rules and regulations set by the ethical committee of university of Lahore will be followed while conducting the research and the rights of the research participants will be respected.

\section{Secrecy of data}

The creators express that they have followed the shows of their work put on the scattering of patient information and that all the patients that are for the evaluation have gotten adequate data and have given their educated agree recorded as a printed variant to take part in that overview and we ensure that their privacy is important to us and there whole data is in confidentiality.

\section{Informed consentand right to privacy}

We have gotten the informed consent with respect to patients and to other subjects that are referred in the article. Everything is in confidentiality and all the things that are mentioned in the article are with the permission of every single person which is considered in Article.

\section{Conflict of interest} in this study.

We declared that there is no conflict of interest

\section{REFRENECE}

1. Salaffi, F., Carotti, M., Tardella, M., Di Carlo, M., Fraticelli, P., Fischetti, C., ... \& Gabrielli, A. (2020). Computed tomography assessment of evolution of interstitial lung disease in systemic sclerosis: Comparison of two scoring systems. European journal of internal medicine, 76, 71-75.

2. Dai, Y., Wang, W., Yu, Y., \& Hu, S. (2020). Rheumatoid arthritis-associated interstitial lung disease: an overview of epidemiology, pathogenesis and management. Clinical Rheumatology, 1-10.

3. O'Dwyer, D. N., Armstrong, M. E., Cooke, G., Dodd, J. D., Veale, D. J., \& Donnelly, S. C. (2013). Rheumatoid arthritis (RA) associated interstitial lung disease (ILD). European journal of internal medicine, 24(7), 597-603.

4. Cocconcelli, E., Balestro, E., Biondini, D., Barbiero, G., Polverosi, R., Calabrese, F., ... \& Saetta, M. (2019). High-resolution computed tomography (HRCT) reflects disease progression in patients with idiopathic pulmonary fibrosis (IPF): relationship with lung pathology. Journal of clinical medicine, 8(3), 399.

5. Sabri, Y. Y., Taymour, T. A., Shaban, M. M., \& Kamel, S. F. (2016). The role of HRCT in evaluation of thoracic manifestations of rheumatoid arthritis. Egyptian Journal of Chest Diseases and Tuberculosis, 65(1), 319-323. 
6. Nurmi, H. M., Kettunen, H. P., Suoranta, S. K., Purokivi, M. K., Kärkkäinen, M. S., Selander, T. A., \& Kaarteenaho, R. L. (2018). Several highresolution computed tomography findings associate with survival and clinical features in rheumatoid arthritis-associated lung disease. Respiratory medicine, 134, 24-30.

7. Bongartz, T., Nannini, C., Medina-Velasquez, Y. F., Achenbach, S. J., Crowson, C. S., Ryu, J. H., ... \& Matteson, E. L. (2010). Incidence and mortality of interstitial lung disease in rheumatoid arthritis: a population-based study. Arthritis \& Rheumatism, 62(6), 1583-1591.

8. Emam, E. M. (2016). Role of High Resolution Computed Tomography in Diagnosing Lung Diseases (Doctoral dissertation, Sudan University of Science and Technology).

9. Elhaj, S. A. A. (2017). Studyof Lung Lesion Using High Resolution Computed Tomography (Doctoral dissertation, Sudan University of Science and Technology).

10. Pérez-Dórame, R., Mejía, M., Mateos-Toledo, H., \& Rojas-Serrano, J. (2015). Rheumatoid arthritisassociated interstitial lung disease: lung inflammation evaluated with high resolution computed tomography scan is correlated to rheumatoid arthritis disease activity. Reumatología Clínica (English Edition), 11(1), 12-16.

11. Salaffi, F., Carotti, M., Bosello, S., Ciapetti, A., Gutierrez, M., Bichisecchi, E., ... \& Ferraccioli, G. (2015). Computer-aided quantification of interstitial lung disease from high resolution computed tomography images in systemic sclerosis: correlation with visual reader-based score and physiologic tests. BioMed Research International, 2015.

12. Yamakawa H, Sato S, Nishizawa T, Kawabe R, Oba T, Kato A, Horikoshi M, Akasaka K, Amano M, Sasaki H, Kuwano K. Impact of radiological honeycombing in rheumatoid arthritis-associated interstitial lung disease. BMC pulmonary medicine. 2020 Dec;20(1):1-7.

13. Li, L., Gao, S., Fu, Q., Liu, R., Zhang, Y., Dong, X., ... \& Zheng, Y. (2019). A preliminary study of lung abnormalities on HRCT in patients of rheumatoid arthritis-associated interstitial lung disease with progressive fibrosis. Clinical rheumatology, 38(11), 3169-3178.

14. Wu, E. K., Ambrosini, R. D., Kottmann, R. M., Ritchlin, C. T., Schwarz, E. M., \& Rahimi, H. (2019). Reinterpreting evidence of rheumatoid arthritis-associated interstitial lung disease to understand etiology. Current rheumatology reviews, 15(4), 277-289.

15. Chandna, P., \& Yadav, R. K. Interpretation of High Resolution CT of the Lung. Reconstruction, 4, 15.

16. Ley, B., Bradford, W. Z., Vittinghoff, E., Weycker, D., du Bois, R. M., \& Collard, H. R. (2016). Predictors of mortality poorly predict common measures of disease progression in idiopathic pulmonary fibrosis. American journal of respiratory and critical care medicine, 194(6), 711-718.

17. Forestier, A., Le Gouellec, N., Béhal, H., Kramer, G., Perez, T., Sobanski, V., ... \& Rémy-Jardin, M. (2020, December). Evolution of high-resolution CT-scan in systemic sclerosis-associated interstitial lung disease: description and prognosis factors. In Seminars in arthritis and rheumatism (Vol. 50, No. 6, pp. 1406-1413). WB Saunders.

18. Dong, H., Julien, P. J., Demoruelle, M. K., Deane, K. D., \& Weisman, M. H. (2019). Interstitial lung abnormalities in patients with early rheumatoid arthritis: A pilot study evaluating prevalence and progression. European journal of rheumatology, 6(4), 193.

19. Arnett, F. C., Edworthy, S. M., Bloch, D. A., Mcshane, D. J., Fries, J. F., Cooper, N. S., ... \& Hunder, G. G. (1988). The American Rheumatism Association 1987 revised criteria for the classification of rheumatoid arthritis. Arthritis \& Rheumatism: Official Journal of the American College of Rheumatology, 31(3), 315-324.

20. Demedts, M., \& Costabel, U. (2002). ATS/ERS international multidisciplinary consensus classification of the idiopathic interstitial pneumonias.

Cite This Article: Hussnain Rashid Butt et al (2021). The use of High Resolution CT (HRCT) for the Evaluation of Lung Parenchyma in patient with Arthritis. EAS J Radiol Imaging Technol, 3(2), 49-56. 